\title{
LOS PLANOS DE JUAN TALAVERA DE LA VEGA PARA LAS OBRAS DERIVADAS DE LA DONACIÓN DE TERRENOS PARA LA CREACIÓN DEL PARQUE DE MARÍA LUISA DE SEVILLA
}

\author{
JUAN TALAVERA DE LA VEGA'S PLANS OF WORKS \\ DERIVED FROM THE LAND DONATION TO CREATE \\ THE PARQUE DE MARÍA LUISA IN SEVILLE
}

\author{
Amparo Graciani García \\ Universidad de Sevilla, España \\ agracianig@us.es
}

\begin{abstract}
Juan Talavera y de la Vega, arquitecto del Palacio de San Telmo, fue el responsable del diseño de las construcciones que debían realizarse en el palacio a consecuencia de la donación por parte de la infanta María Luisa Fernanda de un área de sus jardines a la ciudad de Sevilla para crear un parque público. En agosto de 1893, Talavera remitió al Ayuntamiento los planos que se analizan en estas páginas. Los adjuntaban a un informe donde explicaba la incidencia de la apertura de la nueva avenida que servía de límite a los terrenos cedidos y de la demolición de diferentes construcciones, en especial, el antiguo Convento de San Diego, dedicado a las caballerizas y estancias de servicios del palacio y las viviendas de su personal.

Palabras clave: Convento de San Diego, Palacio de San Telmo, arquitectura neomudéjar, siglo XIX, Sevilla

María Luisa Fernanda, Duchess of Montpensier, donated an important part of her gardens of St. Telmo's Palace to the city of Seville in order to create a public park. Juan Talavera de la Vega, chief architect of the palace, was responsible for the design of buildings to be carried out in the palace as a result of the cession. The plans we study in these pages, were submitted to Town Hall by in August 1893. They were attached to a report explaining the impact of opening the new avenue bordering the ceded lands, and demolishing different buildings dedicated to stables, palace service rooms and staff housing, especially the old St. Diego's Convent.
\end{abstract}

Keywords: St. Diego's Convent, St. Telmo's Palace, neomudejar architecture, XIX century, Sevilla 
El 19 de junio de 1893 se concretaba en escritura pública la donación a la ciudad de Sevilla de una amplia extensión -más de 18 ha.-- de los jardines del Palacio de San Telmo por parte de la infanta María Luisa Fernanda de Borbón, hermana de Isabel II y duquesa viuda de Montpensier. Esta superaba con creces la solicitud del alcalde, José Bermúdez Reina, de abrir una vía cruzando los jardines, que como prolongación de la Avenida de la Industria (actual Menéndez y Pelayo) desembocara en el muelle del Guadalquivir a fin de facilitar su conexión con la estación de Cádiz. Tan importante hito urbanístico de la Sevilla decimonónica ${ }^{1}$ sería determinante en la configuración del recinto de la Exposición Iberoamericana de 1929 y la consiguiente expansión Sur de la ciudad.

La historiografía precedente ${ }^{2}$ ha analizado ampliamente las condiciones impuestas por la infanta, recogidas en el expediente conservado en el Archivo Municipal de Sevilla ${ }^{3}$. La principal, que el espacio donado nunca dejara de ser parque público, previendo - de suceder- la rescisión del contrato y la reversión de los terrenos a la infanta o a sus herederos y legítimos sucesores, quedando a su favor las mejoras que se hubieran realizado. Además, las nuevas caballerizas y las dependencias auxiliares del palacio que el Ayuntamiento se había ofrecido a costear como resultado de la necesidad de demoler el antiguo Convento de San Diego ${ }^{4}$ donde éstas se ubicaban ${ }^{5}$, debían ser construidas en un año desde el otorgamiento de las escrituras y bajo la responsabilidad del arquitecto de la casa, Juan Talavera de la Vega $^{6}(1832-1908)$.

${ }^{1}$ SUÁREZ GARMENDIA, José Manuel: Arquitectura y urbanismo en la Sevilla del siglo XIX, Sevilla, 1986.

${ }^{2}$ VÁZQUEZ SOTO, José María; VÁZQUEZ CONSUEGRA, Guillermo y TORRES VELA, Javier: San Telmo. Biografía de un Palacio. Sevilla, 1990; FALCÓN MÁRQUEZ, Teodoro: El Palacio de San Telmo. Sevilla, 1991; RIBELOT CORTÉS, Alberto: Vida azarosa del Palacio de San Telmo. Su historia y administración eclesiástica. Sevilla, 2001; LLEÓ CAÑAL, Vicente: "El Palacio de San Telmo en el siglo XIX”. PH: Boletín del Instituto Andaluz del Patrimonio Histórico, 51, 2004.

${ }^{3}$ AMSe. CA (Archivo Municipal de Sevilla. Colección Alfabética). Parque de la Ciudad. 1890-1914, Caja 513, Varios 445. Expediente sobre la Donación de gran parte de los terrenos de los jardines del Palacio de San Telmo por la Infanta María Luisa Fernanda de Borbón, duquesa de Montpensier, a la ciudad de Sevilla.

${ }^{4}$ TENA RAMÍREZ, Carmen de: "Convento de San Diego de Alcalá", en Fondos y procedencias: Bibliotecas en la Biblioteca de la Universidad de Sevilla, pp. 209-216; VÁZQUEZ SOTO, José María: Biografía..., op. cit., p. 107, nota 1.

${ }^{5}$ Sobre la adquisición del palacio por los duques en 1849, su proceso de enajenación y las adquisiciones realizadas al Estado y a particulares, entre ellas la Huerta de San Diego, vid. RIBELOT, CORTÉS, Alberto: Vida azarosa..., op. cit., v. 1, pp. 106-127.

${ }^{6}$ Sobre su figura y su producción vid. SUÁREZ GARMENDIA, José Manuel: $A r$ quitectura y urbanismo..., op. cit., pp. 255-259. Balbino Marrón y Ranero (1812-1867) fue responsable de las obras de adaptación del Colegio de Mareantes a Palacio para la instalación de los duques desde 1849 a su muerte; en 1868 le sucedió Talavera, que contó con la 
En el Archivo Municipal de Sevilla se conservan cuatro planos que, una vez aprobados por la infanta, Talavera remitió al Ayuntamiento el 28 de agosto de $1893^{7}$ anexos a un informe en el que refería la índole, el destino, la disposición y las demás circunstancias de las edificaciones a segregar y reconstruir (qué se destruiría y a costa de quién, y qué material podría ser reaprovechado ${ }^{8}$ ) así como lo relativo a la construcción de puestos de guardia en los nuevos límites de los jardines $^{9}$. Con ello, Talavera daba respuesta a la solicitud de la ponencia creada en el seno de la Comisión de Obras Públicas del Ayuntamiento, de la que F. de Floranes, Campos, Checa y Corona formaban parte y a la que, con el asesoramiento del Arquitecto Municipal -José Gallegos Díaz- y el propio Talavera, se le encomendó todo lo relativo a los proyectos, planos y construcciones a realizar a cargo del Ayuntamiento en los Jardines de San Telmo ${ }^{10}$.

Los tres primeros planos representan las plantas baja ${ }^{11}$ (figura 1), primera $^{12}$ (figura 2) y segunda ${ }^{13}$ (figura 3), respectivamente, del antiguo Convento de San

colaboración de los maestros de obra Bartolomé Botella y Antonio de Padura. Sobre las actuaciones de ambos, vid. FALCÓN MÁRQUEZ, Teodoro: El Palacio..., op.cit., pp.193219 y $220-243$.

${ }^{7}$ AMSe. CA, Caja 513, Varios 445. Fol. 68: pl. II-1-31; fol 69: pl. II-2-23; fol. 70: pl. II-1-32; fol. 71: pl. II-1-33.

8 "Nota comparativa de las dependencias que en el edificio de San Diego se utilizan y las que se han de hacer en San Telmo para sustituirlas". Sevilla, 22 de agosto de 1893. Firmado: Juan Talavera. AMSe. CA, Caja 513, Varios 445.

${ }^{9}$ Hasta el momento el recinto había contado con una casa de guarda en la puerta del ángulo en el Prado, frente al huerto de Mariana, y dos en la glorieta de la Fuente del Abanico. Así se aprecia en el plano de Sevilla de Manuel Álvarez-Benavides y López y Carlos Santigosa (1868) (Vid. Planos de Sevilla. Colección histórica: 1771-1918. Sevilla, 1992, plano núm. 5, p.18) (fig.5).

Los planos y el informe son referidos por Suárez Garmendia y posteriormente por otros autores (SUÁREZ GARMENDIA, José Manuel: Arquitectura y urbanismo..., op. cit., pp. 291-292; FALCÓN MÁRQUEZ, Teodoro: El Palacio..., op. cit., p. 227).

${ }_{10}$ Acta de la Comisión de Obras Públicas del Ayuntamiento de Sevilla. Sevilla, 8 de agosto de 1893. AMSe, CA, Caja 513, Varios 445.

${ }^{11}$ Plano (planta) del Palacio de SAN TELMO / J. TALAVERA [1893]. 50,5 (al.) x 75 (an.) $\mathrm{cm}$. Escala: $9,1 \mathrm{~cm}=20 \mathrm{~m}$. Papel de hilo satinado. Tintas negra y rosada. Es copia firmada por el arquitecto, en lado inf., leyenda con números sobre divisiones del palacio situado entre Huerta de San Diego y los Jardines. AMSe, CA, Caja 513, Varios 445, fol. 68. Pl. II-1-31.

12 Plano (planta) del piso primero del Palacio de SAN TELMO. Sin firmar ni fechar. [J. TALAVERA]. 37,5 (al.) x 50 (an.) cm. Escala: $9,1 \mathrm{~cm}=20 \mathrm{~m}$. Papel de hilo satinado. Tintas negra y rosada. Deterioro por roce de pliegue. AMSe, CA. Caja 513, Varios 445, fol. 70. Pl. II-1-32.

${ }^{13}$ Plano (planta) del piso segundo del Palacio de SAN TELMO. Sin firmar ni fechar. [J. TALAVERA]. 38 (al.) x 51 (an.) cm. Escala: $9,1 \mathrm{~cm}=20 \mathrm{~m}$. Papel de hilo satinado. Tintas negra y rosada. AMSe, CA. Caja 513, Varios 445, fol. 71. Pl. II-1-33. 
Diego $^{14}$ en 1893, a fin de justificar los edificios plasmados en el cuarto plano (figura 4) cuyas obras el Ayuntamiento debía sufragar. Aunque ninguno de los cuatro está acotado, sus escalas gráficas permiten determinar las medidas. Éstos parecen haber sido realizados en dos momentos diferentes y con distinta mano, pues mientras el de la planta baja de San Diego lo firma Juan Talavera y se representa con orientación Norte-Sur, los del piso principal y segundo no están firmados, su orientación es Sur-Norte y su grafía menos cuidada; además, al aplicar las escalas correspondientes para determinar las medidas absolutas de las salas se detectan desviaciones métricas entre ellos. El escaso tiempo transcurrido entre el encargo a Talavera por parte de la ponencia de la Comisión de Obras Públicas -nombrada el 8 de agosto- y la remisión del documento -el día 22-, y la corta incidencia de los planos de planta principal y segunda pudieron hacer que Talavera remitiera planos no realizados exprofeso; las prisas, ante la necesidad de sacar a subasta las obras ${ }^{15}$, justificarían algunas contradicciones (siempre de poco interés) entre el documento remitido y el plano de planta baja, así como alguna falta de correspondencia entre las grafías del plano y su leyenda. Al no estar representada la iglesia en los planos de planta primera y segunda, cabe pensar que éstos pueden corresponder a la remodelación que cuarenta años antes, a raíz de la compra de la finca, efectuaron los propios duques en algunas dependencias del antiguo convento para adaptarlas a las necesidades del servicio de palacio.

El otro plano ${ }^{16}$ aúna diferentes representaciones de las seis edificaciones que habrían de ser costeadas por el Ayuntamiento. Lo firma Juan Talavera, referido como "Arquitecto de SAR", quien realizó éste y el de la planta baja de San Diego en cumplimiento a su encargo, por lo que aunque no están fechados los datamos en agosto de $1893^{17}$. Ambos (figuras 1 y 4) serán objeto de un análisis detallado en estas páginas.

${ }^{14} \mathrm{El}$ convento, de la rama alcantarina de los franciscanos, fue fundado a finales del XVI. Una síntesis de su historia se recoge en VÁZQUEZ DE SOTO, José María: Biografí...., op. cit., pp. 90-91.

${ }^{15}$ El Gobierno Civil otorgó la excepción de subasta de las obras, por la imposibilidad de convocarla ante la negativa del arquitecto de proporcionar presupuestos detallados (no habiéndose demolido el convento) y por la conveniencia de generar trabajos que evitaran alteraciones de orden público por la crisis obrera del momento. Vid. Escritos del Ayuntamiento de Sevilla al Gobernador Civil de la Provincia. Sevilla, 23 de noviembre y 31 de diciembre de 1893, respectivamente. AMSe, CA, Caja 513, Varios 445.

${ }^{16}$ Planos (plantas y alzados en una sola pieza) de diversas dependencias del PALACIO DE SAN TELMO / J. TALAVERA. arquitecto de S.A.R. [1893]. 75 (al.) x 78 (an.) cm. Papel de hilo satinado. Tintas azul, negra y roja. Planos: plantas (Escala 1:100) del Cuerpo de Guardia, caballerías, cocheras, lavadero y cuarto de plancha; alzados (Escala 1:50) de estufa, pabellón de ángulo y casa del guarda. AMSe, CA. Caja 513, Varios 445, fol 69. Pl. II-2-23.

${ }^{17}$ Esta información ha sido trasladada a los responsables del AMSe para la corregir a catalogación actual, fechada en 1890. 
La información escrita que la copia del plano de planta baja de las dependencias conventuales (figura 1) aporta en su leyenda puede completarse con la incluida en el informe de Talavera y la que se desprende el análisis del propio plano y de otras fuentes. En dicho informe refiere a las construcciones dispersas en los jardines y, sobre todo, las partes del convento, sus características y dimensiones y las transformaciones que con el tiempo experimentaron.

En el plano que nos ocupa, las estancias conventuales que habrían de ser demolidas a costa del Ayuntamiento (la iglesia, la Capilla del Oratorio, la sacristía, la casa del portero, las cuadras, los lavaderos, la cochera y algunas habitaciones) $)^{18}$, se incluyen -parcial o totalmente- entre dos líneas que indican el emplazamiento previsto para las verjas que, por el lado del parque y por el de los jardines de San Telmo, delimitarían la avenida de nuevo trazado ${ }^{19}$. El informe refiere otras que el Ayuntamiento debía demoler a su costa otras construcciones que no se reflejan en el plano por estar entre el convento y el Paseo de las Delicias: la Casa de la Torre, una amplia estufa acristalada - de $70 \mathrm{~m}$ x $8 \mathrm{~m}$ - y estructura de hierro, y las instalaciones que la rodeaban, en concreto diferentes estufas (una de bambú y otras en el suelo para reproducción), una alberca de plantas acuáticas y varios pilones. En su escrito, el arquitecto alude continuamente a la figura de SA, indicando los gastos de demolición y reconstrucción que quedarían a su cargo, así como los elementos que rodeaban la estufa principal. También insiste en la menor envergadura de las nuevas construcciones respecto a las demolidas y en la reestructuración del servicio, cuestiones en cualquier caso lógicas por las menores necesidades de la anciana infanta, cuyos jardines se habían visto muy reducidos.

Haciendo uso de la escala gráfica que el plano contiene, podemos determinar las dimensiones generales del conjunto conventual y de sus diferentes elementos, con mayor claridad que la que ofrece la minuciosa descripción del convento que se incluye en el protocolo de venta al duque de Montpensier ${ }^{20}$. Así, podemos afirmar que la extensión del antiguo convento superaba los $6.000 \mathrm{~m}^{2}\left(6.162,80 \mathrm{~m}^{2}\right.$, según nuestros cálculos). También que, aunque las fuentes inciden en que se encontraba en el solar donde se construiría el Casino de la Exposición Iberoameri-

${ }^{18}$ Según el informe, los lavaderos ocupaban $177 \mathrm{~m}^{2}$ y las cocheras (para dieciséis carros), $504 \mathrm{~m}^{2}$. Las cuadras tenían capacidad para veinte caballos y veinte mulas; las caballerizas contaban con sesenta pesebres y se organizaban en dos áreas; una (de treinta y dos pesebres, distribuidos en dos crujías) tras el presbiterio, y otra (de treinta y ocho) dando al jardín. El número de pesebres no coincide con lo indicado en el plano, donde para cada ala se refiere treinta y cuatro.

${ }^{19}$ Talavera incorporó estas líneas posteriormente, a solicitud de la Comisión de Obras Públicas (Informe de la Comisión de Obras Públicas del Ayuntamiento al Cabildo de la Ciudad. Sevilla, 22 de agosto de 1893. AMSe, CA, Caja 513, Varios 445).

${ }^{20}$ En este protocolo se recogen las dimensiones y la forma del área conventual, en varas y pulgadas (VÁZQUEZ SOTO, José María: Biografía..., op. cit., p. 93). 
cana, una gran parte se encontraba al otro lado de la Avenida de María Luisa; de hecho, calculamos que la extensión ocupada al otro lado de la "verja del lado de San Telmo" sería de $2.835,77 \mathrm{~m}^{2}$, y que tras la "verja del lado del Parque" quedarían 2.045,08 $\mathrm{m}^{2}$; considerando metros lineales, a un lado y otro distarían 59,40 y $51,65 \mathrm{~m}$, respectivamente. Estas referencias evidencian que el convento de San Diego se extendía al solar actualmente ocupado por el Restaurante La Raza, resultado de las transformaciones acometidas sobre el Pabellón de Información de la Iberoamericana. La Glorieta de San Diego, diseñada en el acceso al recinto del Certamen, llevaba el nombre del convento en su recuerdo, no por ocupar su emplazamiento. La leyenda del plano recoge los usos que para el servicio del Palacio se daba a las distintas dependencias conventuales; a excepción de la iglesia (núm. 5) y de la capilla (núm. 6) que, según de Arana de Varflora, originariamente se denominaría del Oratorio $^{21}$, no alude el destino original de la salas.

Pocas referencias descriptivas existen del Convento original, construido a expensas de la ciudad hacia 1580 para religiosos de la Orden de San Francisco de la provincia de San José. Según González de León “....era mediano, estrecho en viviendas y celdas como para frailes descalzos; pero con todas las comodidades necesarias, y una dilatada huerta" 22 . El cronista de los frailes menores, Fray Francisco de Jesús María, describía su emplazamiento pero no su interior ${ }^{23}$.

En uno de los contados testimonios gráficos del convento conocidos hasta la fecha ${ }^{24}$, el Plano de Olavide (1771), se aprecian sus huertas y los olmos que lo separaban de la Fábrica de Tabacos. El plano de Talavera permite apreciar cómo en 1893 perduraban aún las líneas básicas de la construcción original, pese a las adaptaciones realizadas por el filántropo inglés Nathan Wertherel125 (a quien el Ayuntamiento cedió el convento que estaba abandonado desde $1784^{26}$ ) para

${ }^{21}$ ARANA DE VARFLORA, Fermín: Compendio histórico descriptivo de la muy noble y muy leal ciudad de Sevilla metrópoli de Andalucía. Sevilla, 1789, p. 49.

${ }^{22}$ GONZÁLEZ DE LEÓN, Félix: Noticia artística histórica y curiosa de todos los edificios públicos, sagrados y profanos de esta muy noble, muy leal, muy heroica e invicta Ciudad de Sevilla, y de muchas casas particulares, t. II, Sevilla, 1844, pp. 167-168.

${ }^{23}$ VÁZQUEZ SOTO, José María: Biografía..., op. cit., pp. 84-85.

${ }^{24}$ Ibídem, p. 87. El autor refiere las escasas representaciones del convento.

${ }^{25}$ Sobre Nathan Wertherell (1749-1831), figura fundamental en el proceso industrializador sevillano, vid. ÁLVAREZ PANTOJA, María José: "Nathan Wertherell, un industrial inglés en la Sevilla del antiguo régimen". Moneda y crédito, 143, 1977, pp. 133-186; GÓMEZ MURGA, Ezequiel; BARBERO RODRÍGUEZ, Jesús y DINGR, Charlotte Luisa: "Nathan Wertherell (1747-1831), un inglés por tierras de Dos Hermanas". Dos Hermanas. Ferias y Fiestas, 63, 2006, pp. 73-79. Tras ser adquirido en 1842 por Clara Osorno, viuda de José de Checa, en 1849, el duque compró la finca y sus dependencias.

${ }^{26}$ A comienzos de año, los franciscanos descalzos que lo habitaban hubieron de abandonarlo tras una fuerte riada (vid. PALOMO, Francisco de Borja: Historia crítica de las 
instalar la Fábrica de Curtidos de San Diego entre 1785 y 179027), y, posteriormente, por los duques de Montpensier, que en 1849 adquirieron la Huerta de San Diego y emplazaron sobre los restos del convento - del que restaba muy poco ${ }^{28}$ las dependencias auxiliares para el personal y servicio del Palacio de San Telmo. El Plano de Olavide muestra un modelo habitual en los conventos de la orden, organizado en torno a dos amplios claustros: un primer claustro, destinado a albergar a los frailes y que daba acceso a la iglesia y un segundo claustro o interno. En este caso, el ábside de la iglesia se integraría en la panda o crujía de separación entre ambos. La existencia en el plano de Talavera de un acceso cegado en el extremo NO del convento y el apeadero contiguo, así como su mayor proximidad respecto al núcleo urbano, corroboran que su primer claustro correspondería al occidental.

En el plano se aprecia que la iglesia, conforme al espíritu franciscano, era muy sencilla: de planta de cajón (de 14,75 x 5,2 m medidos a partir de la escala gráfica), con cabecera de testero plano y abierta al crucero por un arco toral de medio punto. Presentaría coro y sotocoro a los pies; en el plano de Talavera estos aparecen cerrados y aislados de la nave lo que debió realizarse en la etapa de los duques ya que consta que en el momento de la compra de San Diego este espacio era un gran almacén de casca ${ }^{29}$. La nave central de la iglesia (según el informe, "la parte que sirve para la suela" ${ }^{30}$ ) se cubriría con cañón cilíndrico. Sobre el crucero y la capilla (que sabemos era la del Oratorio) abierta al crucero en el lado del Evangelio, Talavera representa sendas cúpulas sobre pechinas; mientras la de la capilla es esférica, la del crucero es secante en sus muros Norte y Sur, por las proporciones rectangulares del crucero $(6,8 \times 5,2 \mathrm{~m})$ cuya longitud se relaciona modularmente con la de la propia nave de la iglesia (1:2). Su secancia-que al no producirse en los lados Este y Oeste del presbiterio no es vaída- hace pensar en una posible reforma del sector oriental de la Iglesia. Conforme al modelo habitual y como se representa en el plano de Olavide, las cubiertas de iglesia se trasdosarían con armadura de madera, a dos aguas en la nave, con una tercera vertiente en la cabecera. En el plano de Talavera sólo dos naves se representan con bóvedas de arista: una sobre una sala de guadarnés (núm. 11) próxima al crucero de la iglesia, y otra en el ángulo SE del conjunto en un espacio dedicado a capilla del personal de servicio del palacio. Ambas cubiertas se referencian en el protocolo de

riadas o grandes avenidas del Guadalquivir en Sevilla desde su reconquista hasta nuestros días. Sevilla, 1878, p. 403). Se trasladaron al antiguo noviciado de los jesuitas de San Luis.

${ }^{27}$ ORTEGA, Ángel: "La Provincia de San Diego en Andalucía y la Misión de Marruecos. Documentos inéditos". Archivo Ibero-Americano. Estudios históricos sobre la orden franciscana en España y sus misiones, XXIII, 1917, pp. 161-205).

${ }^{28}$ GONZÁLEZ DE LEÓN, Félix: Noticia artística, ..., op.cit., p. 167.

${ }^{29}$ VÁZQUEZ SOTO, José María: Biografía..., op. cit., p. 93.

${ }^{30}$ Ibídem, p. 95. 
venta al duque de Montpensier, donde se indica que existían "bóvedas por arista de fábricas de ladrillos en dos habitaciones bajas" 31 . La iglesia y la mayor parte del convento se construyeron con fábrica de tapial encadenado en ladrillo; algunas partes se ejecutaron en mampostería y otras con ladrillo ${ }^{32}$.

Las estructuras claustrales aparecen más alteradas en el plano, como consecuencia de las reformas realizadas por Wertherell quien convirtió sus celdas y dormitorios en talleres de la curtiduría ${ }^{33}$, estancias a las que los duques darían nuevos usos. La transformación es especialmente evidente en el claustro occidental que el inglés compartimentó en tres espacios abiertos, generando un patio interior de doble acceso rodeado de talleres.

En el plano de Talavera, se marcan tres accesos al amplio recinto representado. El más occidental comunicaba el jardín con un espacio abierto al patio interior de la antigua curtiduría, cuyas estancias pasaron a destinarse a guardarmas y habitaciones del servicio. Los otros se abrían al Prado de San Sebastián; mientras el más oriental (en el entorno de la fuente de Hispania construida por Traver en la entrada de la Exposición Iberoamericana) daba acceso al claustro interno o segundo, el central (en el arranque de la posterior Avenida de María Luisa) lo hacía al frente Norte de la iglesia. El detallismo del plano, en el que se refleja el espesor de las jambas, evidencia la existencia de dos accesos en el frente Norte de la fábrica conventual original. Uno, mantenido en la curtiduría y en la etapa palaciega, daba acceso al claustro oriental; el otro, que lo hacía al apeadero que precedía al primer claustro, se representa cegado en el plano de Talavera, lo que se realizó en época de los duques ${ }^{34}$, cuando por las necesidades de comunicación de las dependencias de servicio con el Palacio y con el exterior, se abrió el acceso del frente oeste (que comunicaba el área de servicios con los jardines). El acceso frontal a la iglesia se habría abierto para facilitar paso a la curtiduría, constando su existencia en la escritura de venta al duque de Montpensier.

Según recoge la leyenda del plano, durante la etapa ducal las dependencias del área occidental, más próximas al palacio, se destinaban a guadarnés (núms. 11), habitaciones del servicio (núms. 12), cochera y ("encima”) pajar (núm. 3 ) 35 . Entre las salas del conjunto destaca especialmente esta última (núm. 3) por sus dimensiones $( \pm 30 \mathrm{x} \pm 10 \mathrm{~m})$ y por su singular organización en tres naves longitudinales sobre livianos soportes, y por su apertura al claustro mediante galería de

\section{Ibíd.}

${ }^{32}$ En la escritura de venta al duque de Montpensier se refieren aspectos constructivos y materiales de la curtiduría (Ibíd.).

${ }^{33}$ Ibíd., pp. 94-95. En el protocolo se describen las estancias de la curtiduría y su uso

${ }^{34}$ Ibíd., p. 93. Indica la existencia de tres grandes puertas de entrada en la fachada principal.

${ }^{35}$ La leyenda de la sala 3 refiere "cocheras y encima pajar"; en los otros planos, la sala aparece sólo con planta baja. Pudiera ser un soberado. 
ocho arcos sobre pilares; el alineamiento de los soportes interiores de la sala respecto al cerramiento de las dependencias del claustro oriental, confirma que fue resultado de una intervención posterior vinculada a la apertura del acceso en el frente Norte del conjunto (hacia el Prado de San Sebastián). Por ello, se reforzó el muro exterior de la sala (núm. 3) con tres contrafuertes interiores para soportar el soberado del pajar y también la reorganización de las dependencias de guadarnés contiguas (núms. 11). Al tiempo, se reorganizaría el tramo contiguo al nuevo acceso, dedicándolo a portería (núms. 1), aumentando la profundidad de las salas. En su informe Talavera refiere que las obras de la cochera y el pajar fueron acometidas cuarenta años antes (es decir, siendo Marrón arquitecto de los duques), y que la construcción se encontraba en perfecto estado de conservación.

En el entorno de la iglesia, un eje ortogonal con planta baja y principal, conformado por una estancia perpendicular a su capilla mayor, en sentido NorteSur, y otra, inmediata a los jardines y paralela a la nave de la iglesia, en sentido Este-Oeste (núms. 7), fue dedicado a cuadras con capacidad-según refiere la leyenda- para treinta y cuatro caballos y mulas; en el protocolo del contrato de venta al duque de Montpensier, se diría respecto a esta área (dedicada a obrería) que era "de cañón con lunetos (en la obrería y almacén contiguo)" "36. Por las proporciones de estas dependencias, su marcado carácter longitudinal y su abundante iluminación consideramos que una de ellas pudo corresponder al refectorio conventual; por su posición respecto a la iglesia y su accesibilidad, estimamos que trataría del ala Este-Oeste, y que la que la precede (también, según su numeración -7- dedicada a cuadras) sería la Sala de Profundis. Para facilitar las labores, las estancias inmediatas al encuentro de ambas salas, se dedicaban también al almacenaje de guadarnés, una, y, la otra, a habitaciones del personal, estando dividida en departamentos para los empleados. El plano refleja una menor complejidad en la distribución de las estancias del claustro oriental, más alejado del Palacio. Inmediatas al acceso conventual original, en los pisos bajo y principal, se disponían las salas de lavandería (núms. 12), cuyas pilas se representan en el plano. Al otro lado del acceso, nuevas habitaciones y en el ángulo un depósito de agua (núm. 13). La nave del ángulo SE del conjunto se dedicaba a cochera (núm. 10); también ésta contaba con soberado, dedicado a granero. Junto a ella, una capilla (núm. 6) para el servicio.

El segundo plano en el que nos centraremos (figura 4) recoge seis obras de nueva planta que suplirían las demolidas tras la apertura de la avenida. Recurriendo a dos escalas numéricas distintas ${ }^{37}$, el arquitecto aporta distintas representaciones en función de su necesidad de plasmar los elementos más singulares de cada edificación. De la estufa, su alzado principal; del pabellón de ángulo

${ }^{36}$ Ibíd. p. 95.

${ }^{37}$ Se usa la escala 1:50 en los alzados de pabellón de ángulo y de la casa del guarda, y 1:100 en las restantes construcciones. 
(anteproyecto del que será el popularmente conocido como Costurero de la Reina) y de la casa de guarda, un alzado; del lavadero y cuarto de plancha, su planta y un alzado-sección de su dependencia principal; del cuerpo de guardia, su planta y también del edificio en escuadra dedicado a caballerizas y cochera. Este hecho debe relacionarse con la premura con la que Talavera hubo de trabajar, razón por la que no presentó las correspondientes memorias solicitadas por el Ayuntamiento ${ }^{38}$.

Como ya se ha referido, el plano recoge un anteproyecto del pabellón que habría de sustituir a un edificio de mayor coste, la Casa de la Torre, que situada en la línea divisora de los terrenos cedidos habría de ser demolida. El arquitecto lo denominaba de ángulo por salvar el metro de desnivel producido en el ángulo agudo formado en el encuentro de la verja del lado del río y la avenida, ésta más elevada. Igualmente recoge un alzado de una casa de guarda, ya que debían construirse dos a los lados de la entrada por la prolongación de la Calle de Industria.

El pabellón de ángulo (figura 6) presentaba evidentes similitudes con la casa del guarda (también representada en el plano) (figura 7); ambos edificios eran neomudéjares, y sus paramentos con bíforas de herradura acristaladas sobre estructura férrea, se flanqueaban con torretas curvas en los ángulos. Su emplazamiento preferente condicionaba sus dos pisos y mayor complejidad ornamental, ya que contaba con una triple arcada de su piso superior, polilobulados en las torretas y una cornisa corrida modillonada, frente a los arcos túmidos y la cornisa rota y adentellada de las casas de los guardas. Los edificios diferían también en los merlones -escalonados y curvos o fatimíes, respectivamente-, y en las cornisas, carentes de modillones en el cuerpo central de las casas de los guardas.

Talavera incorporaría variaciones sustanciales al pabellón de ángulo definitivamente ejecutado (figura 8) ${ }^{39}$, que suele datarse en 1893 aunque consta que al finalizar el año no había comenzado, pudiendo construirse en 1894. Otorgándole mayor movimiento, volumetría, carácter ornamental y afinidad con la tradición islámica local, el arquitecto diseñó una pieza clave en el neomudéjar local ${ }^{40}$. Ade-

${ }^{38}$ Este le había solicitado todos los "documentos necesarios y prevenidos por las leyes, cuales son Memorias descriptivas y planos en plantas alzados y secciones, presupuestos detallados con precios de unidades cantidades de material y condiciones de ejecución o facultativas". Se reitera en el informe de la Comisión de Obras Públicas de 22 de agosto (Escrito del Ayuntamiento de Sevilla a Juan Talavera. Sevilla, 6 de julio de 1893 e Informe de la Comisión de Obras Públicas al Cabildo del Ayuntamiento de Sevilla. Sevilla, 22 de agosto de 1893, respectivamente. AMSe, CA, Caja 513, Varios 445).

${ }^{39}$ Falcón refiere que Villar Movellán posee una acuarela del alzado del pabellón (FALCÓN MÁRQUEZ, Teodoro: El Palacio..., Op. cit., p. 242, nota 35). Lleó lo recoge, indicando que procede "de una colección particular de Córdoba" (LLEÓ CAÑAL, Vicente: La Sevilla de los Montpensier. Segunda corte de España. Sevilla, 1997, p. 137).

${ }^{40}$ Villar lo considera el "verdadero primitivo de nuestro neomudéjar" (VILLAR MOVELLÁN, Alberto: Arquitectura del Regionalismo en Sevilla (1900-1935). Sevilla, 2010 
más de elevar con un tercer cuerpo la torreta interior con frente a la fachada a la Avenida de María Luisa, acortó los tramos de paramentos entre las torres en resalte, colmándolos con las arcadas, ahora dobles en ambos cuerpos. También en éstas realizó modificaciones, al sustituir las herraduras por polilobulados y limitar el módulo de doble arco a la fachada principal, con frente a Las Delicias.

En el pabellón construido, Talavera recurriría a la combinación del ladrillo de tradición local (en este caso, el agramilado y bícromo de algunas construcciones mudéjares) con nuevos materiales, el vidrio y el hierro de fundición, que tan importante papel jugaron en el desarrollo de la arquitectura neomusulmana. Aunque este recurso se aprecia en todo el conjunto al incorporar balconadas de hierro a los vanos de la planta superior, es especialmente significativo en su fachada principal; en ella, el arquitecto rompería la monotonía de una idéntica composición de triple arco superponiendo una serré o galería acristalada de tres ligeros arcos de hierro a la arcada inferior y generando un intenso decorativismo con los motivos geométricos de los coloristas cierros acristalados, que se trazan a partir del centro de los arcos.

El arquitecto incorporaba rasgos de la arquitectura histórica sevillana dando un sabor local al pabellón de ángulo inexistente en el proyecto inicial, en una combinación ecléctica de elementos de cronologías diversas. En concreto, Talavera conformó el cuerpo bajo de la fachada principal reinterpretando los arcos cortina de origen almohade y de pervivencia mudéjar; para ello, simplificó la sebka, sustituyó los arcos previsibles (los lambrequines o los polilobulados túmidos, respectivamente) por la triple herradura del Arco de los Pavones del Alcázar de Sevilla (sin el trasdós descentrado propio de los califales de Medina Azahara), reemplazando los capiteles de avispero por los italianos de serie característicos de la arquitectura renacentista sevillana. Todo ello con un guiño a la arquitectura califal, simulando la bicromía de las dovelas características de la sala de oración de la Mezquita de Córdoba y el uso de dovelas escalonadas de la época. Culminó el conjunto incorporando un friso (que repitió en las otras fachadas) de arcos polilobulados ciegos - con sus característicos tondos en cerámica azul cobalto- que remata la caña de la Giralda. En los restantes alzados, reincidiendo en la huella almohade, combinó los capiteles de tradición almohade con los otros nazaríes. La presencia de lo almohade, que en el anteproyecto inicial se limita a un tramo de sebka del arranque de las ventanas del piso alto y a las pequeñas ventanas pentalobuladas de las torres, inspiradas en la Giralda, debe vincularse a la actuación en 1884 de Adolfo Fernández Casanova en el antiguo alminar motivada por los desperfectos generados por el rayo artístico (que estuvo precedida por un amplio estudio documental y la disección de los elementos almohades de la torre, como base para su "reintegración gráfica del primitivo alminar") y, sobre todo, a la

(1 ${ }^{\mathrm{a}}$ ed. 1979), p. 48. 
repercusión de la Memoria Descriptiva realizada en 1888 al finalizar las intervención y su disertación de ingreso en la Real Academia de Bellas Artes de San Fernando en 1892 titulada ¿Cuáles son los elementos generadores del potente arte mauritano y cómo se verificó su desarrollo ${ }^{41}$. Todo ello mezclado con elementos indiscutiblemente nazaríes, como las columnas de fundición de la fachada principal y marmóreas de las restantes fachadas en planta baja.

En el plano de Talavera se representaban otras edificaciones por construir. De una parte, una estufa o invernadero de hierro y cristal, de 38 x $10 \mathrm{~m}$ en sustitución a la que habría que ser destruida, de similar estructura; su nave central, a dos aguas, superaba los $4 \mathrm{~m}$ de altura, cubriéndose a un agua las cuatro restantes. Además, un nuevo lavadero de $91 \mathrm{~m}$, de cuatro plazas y cuarto de plancha y azotea, que se construiría aprovechando las calderas y el mármol de los lavaderos de San Diego ${ }^{42}$. En tercer lugar, unas cocheras de $380 \mathrm{~m}$ en planta, que en el piso alto se dedicaban a estancias para empleados; estas se construirían en el Patio del Apeadero de San Telmo, en el sector NE del conjunto, que experimentó importantes cambios ya que se construyeron unas cocheras (de $100 \mathrm{~m}^{2}$ y con cabida para seis coches) y el cuerpo de guarda y casa del portero situados a la izquierda de su fachada se convirtieron, en planta baja, en cuadra ${ }^{43}$ y en la alta en habitaciones para los empleados de las caballerizas y los jubilados de la casa ${ }^{44}$.

En síntesis, el interés de estos planos estriba fundamentalmente en dos cuestiones. De una parte, el de planta baja del convento muestra algunas características

${ }^{41}$ Esta disertación recoge por primera vez la singularidad del arte almohade (CALAMA RODRÍGUEZ, José María y GRACIANI GARCÍA, Amparo: La restauración decimonónica en España. Sevilla, 1998, pp. 155-164; GONZÁLEZ-VARAS IBÁÑEZ, Ignacio. La Catedral de Sevilla (1881-1890). El debate sobre la restauración monumental. Sevilla, 1994, pp. 249-304). El propio Talavera había llamado la atención sobre el estado de la Giralda en 1880, en el informe que junto a M. Portillo realiza sobre el estado de la Catedral de Sevilla (Vid. GÓMEZ DE TERREROS GUARDIOLA, María del Valle: "La Catedral de Sevilla en 1880: Informe de los arquitectos Manuel Portillo y Juan Talavera sobre el estado del edificio", Laboratorio de Arte, 20, 2007, pp. 371-372).

${ }^{42}$ En el informe, Talavera especificaba que los nuevos lavaderos tendrían ocho pilas, dos calderas y cuatro pilones, y que en el primer piso iría el cuarto de plancha y encima una azotea (de $500 \mathrm{~m}$.) y el secadero de ropa. Indicaba que con desahogo, podrían lavar doce lavanderas y planchar veinte mujeres.

${ }^{43} 500 \mathrm{~m}^{2}$ se usaría en planta baja como cuadras, con veinte pesebres. Las nuevas caballerizas tendrían cabida para diez caballos.

${ }^{44}$ Hasta la fecha, San Diego había albergado treinta familias. El cuerpo de guardia preexistente tenía capacidad para una compañía de capitán y sargento y este sólo para veinte hombres. Vázquez Soto refiere que en 1894, SA contaba con treinta y dos sirvientes, enumerando su dedicación; sólo diecinueve vivían en San Telmo, mientras que los que no tenían cabida en las nuevas instalaciones vivían en sus propios domicilios financiados por la duquesa (VÁZQUEZ SOTO, José María: Biografía..., op. cit., pp. 106 y 109, nota 6). 
de la edificación primigenia, escasamente conocida por otras fuentes, así como las adaptaciones que se realizaron para instalar las dependencias de servicio del $\mathrm{Pa}-$ lacio de San Telmo. De otra, el plano de las nuevas construcciones evidencia los cambios del Pabellón de Ángulo inicialmente proyectado respecto finalmente al ejecutado y que fechamos en 1894. Estas modificaciones fueron sin duda consecuencia de que las obras no hubieron de salir a subasta, y de que el arquitecto no presentara documentos que limitaran tales cambios.

Fecha de recepción: 30 de septiembre de 2014

Fecha de aceptación: 28 de noviembre de 2014

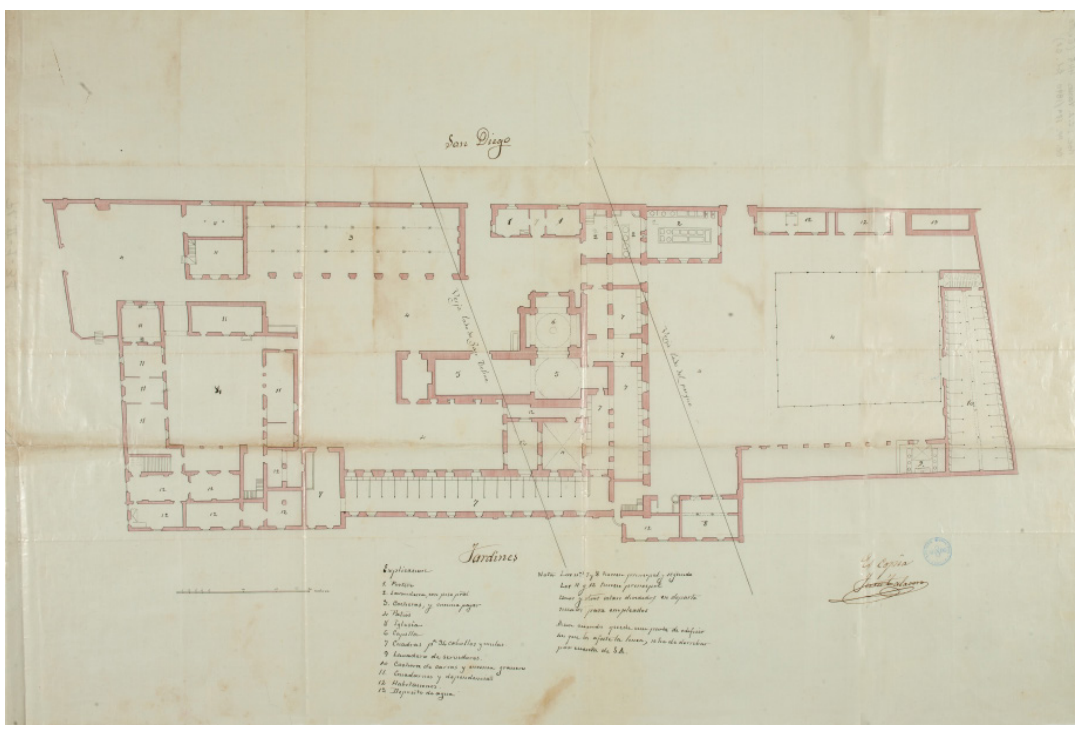

Figura 1. Plano de planta del Palacio de SAN TELMO / J. TALAVERA [1893]. 50,5 (al.) X 75 (an.) cm. Escala: 9,1 c= $20 \mathrm{~m}$ Papel de hilo satinado.

Tintas negra y rosada. Copia firmada por el arquitecto. AMSe, CA, Caja 513, Varios 445, fol. 68. Pl. II-1-31. Fig. 7. Detalle de la figura 4. Casa de Guarda. 


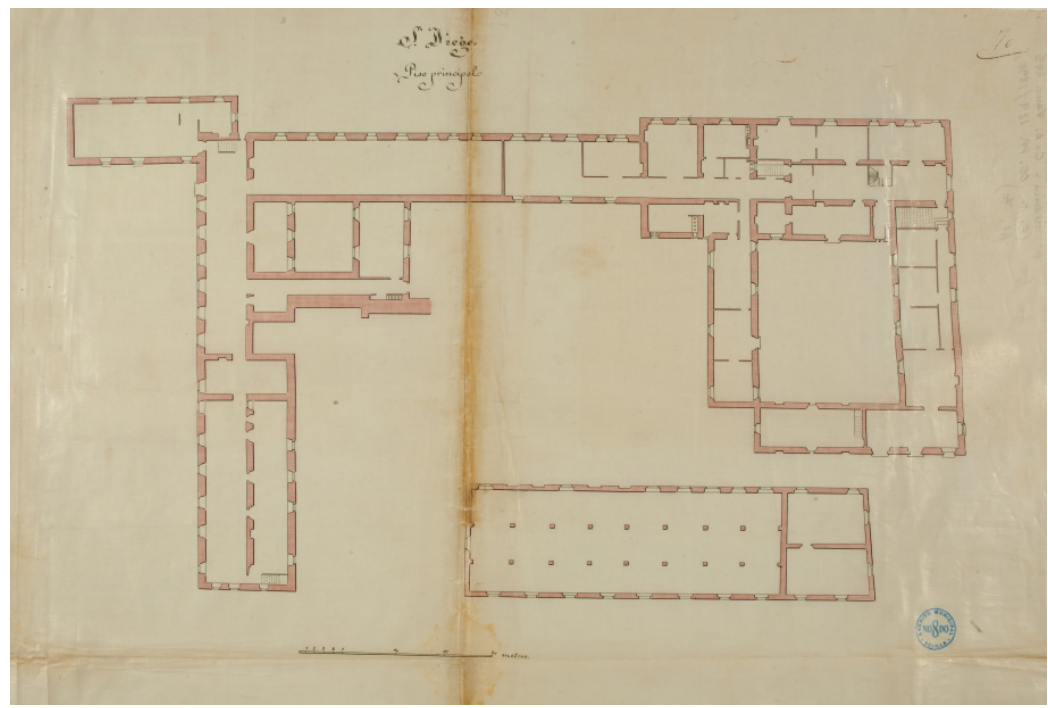

Figura 2. Plano de planta del piso primero del Palacio de SAN TELMO.

Sin firmar ni fechar. [J. TALAVERA]. 37,5 (al.) x 50 (an.) cm.

Escala: 9,1 cm= $20 \mathrm{~m}$ Papel de hilo satinado. Tintas negra y rosada. AMSe, CA. Caja 513, Varios 445, fol. 70. Pl. II-1-32.

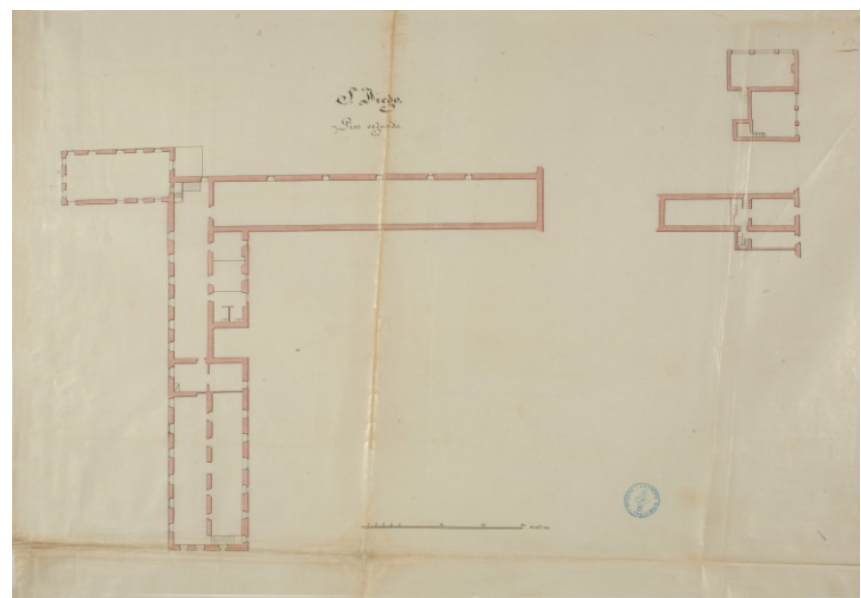

Figura 3. Plano de planta del piso segundo del Palacio de SAN TELMO. Sin firmar ni fechar. [J. TALAVERA]. 38 (al.) X 51 (an.) cm. Escala: 9,1 cm= $20 \mathrm{~m}$ Papel de hilo satinado. Tintas negra y rosada. AMSe, CA. Caja 513, Varios 445, fol. 71. P1. II-1-33. 


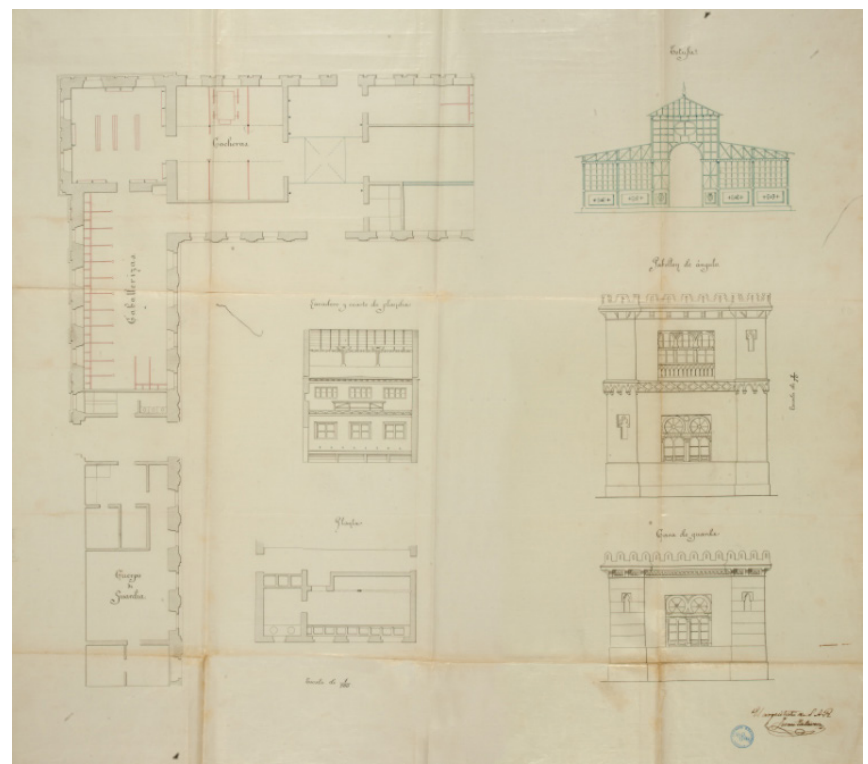

Figura 4. Planos de diversas dependencias del PALACIO DE SAN TELMO / J. TALAVERA, arquitecto de S.A.R. [1893]. 75 (al.) x 78 (an.) cm. Papel de hilo satinado. Tintas azul, negra y roja.

Planos: plantas (escala 1:100) del Cuerpo de Guardia, caballerías, cocheras, lavadero y cuarto de plancha; alzados (escala 1:50) de estufa, pabellón de ángulo y casa del guarda. AMSe, CA. Caja 513, Varios 445, fol 69. Pl. II-2-23.

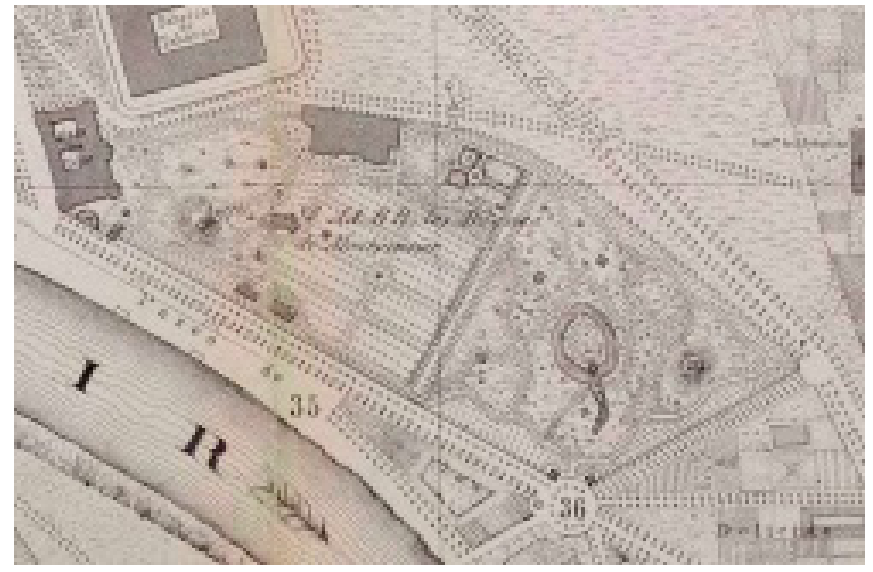

Figura 5. Detalle del plano de Sevilla de Manuel Álvarez-Benavides y López y Carlos Santigosa, 1868 (Planos de Sevilla. Colección histórica: 1771-1918. Sevilla, 1992, plano núm. 5, p.18). 


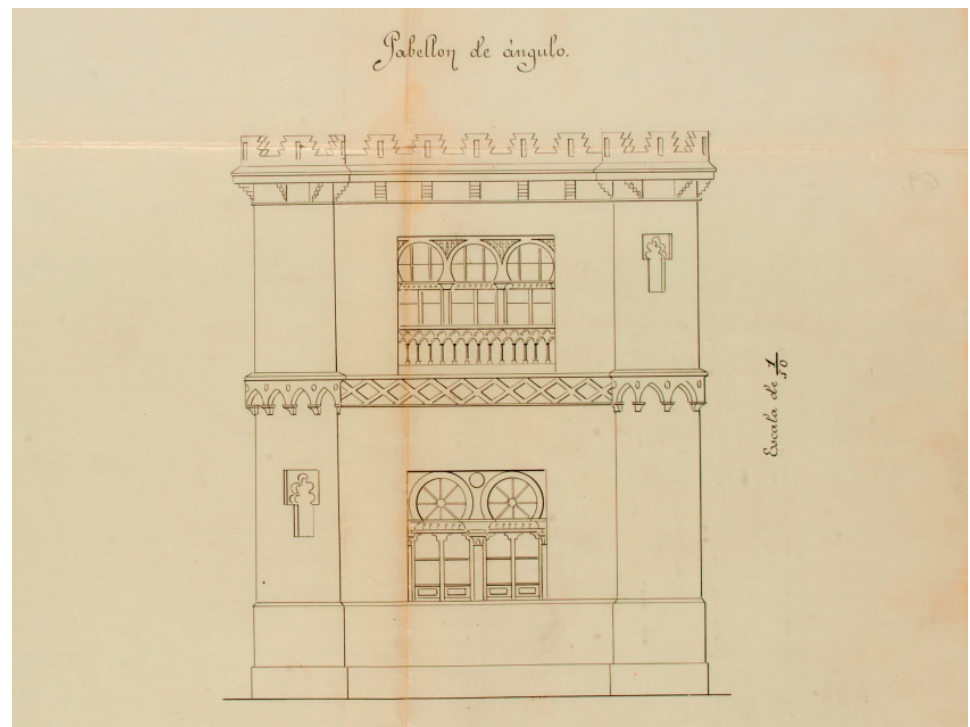

Figura 6. Detalle de la figura 4. Alzado del Pabellón de Ángulo.

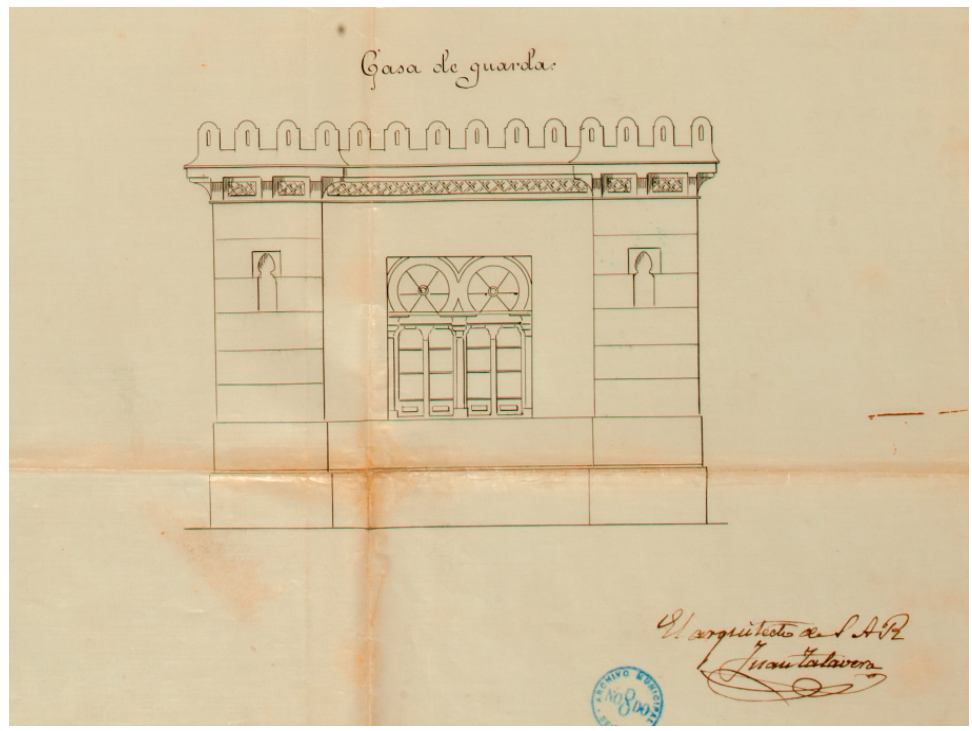

Figura 7. Detalle de la figura 4. Alzado de una casa de guarda. 


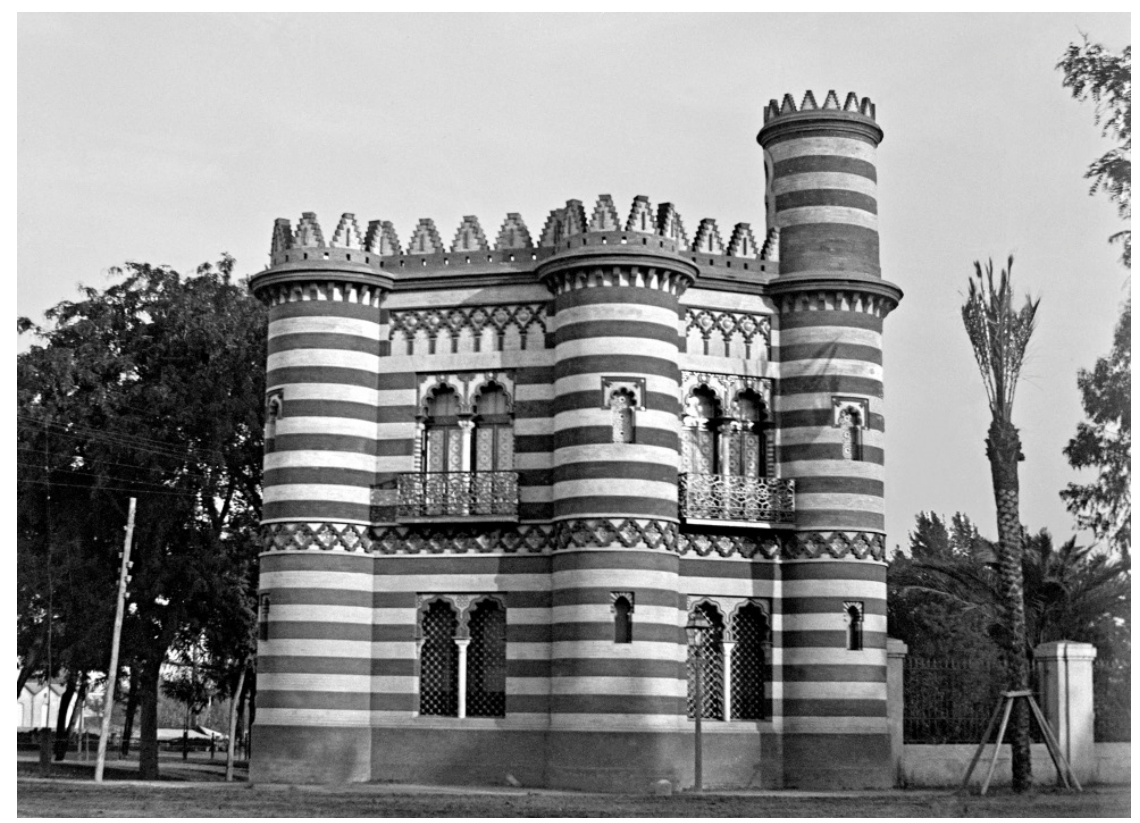

Figura 8. Pabellón de ángulo, construido h. 1894. (C) ICAS-SAHP, Fototeca Municipal de Sevilla, archivo Caparró (ca4_498). 